\title{
Metaphors of Igbo Worldviews on Ghosts as Mystical Realities: Interpretations of Filmic Portrayals as Archetypal and Imaginative Visual Aesthetics in Two Nollywood Films
}

\author{
Emeka Aniago ${ }^{1}$, Chukwuemeka V. Okpara ${ }^{2}$ \& Uche-Chinemere Nwaozuzu ${ }^{3}$ \\ ${ }^{1}$ Senior Lecturer in Department of Theatre E Film Studies, University of Nigeria, Nsukka, Nigeria. \\ ORCID id oooo-ooo3-3194-1463. Email Id: emekaaniago@gmail.com \\ ${ }^{2}$ Senior Lecturer in Department of Fine $\mathcal{E}$ Applied Arts, University of Nigeria, Nsukkka, Nigeria \\ ${ }^{3}$ Associate Professor in Department of Theatre E Film Studies, University of Nigeria, Nsukka, \\ Nigeria
}

\begin{abstract}
This study examines the aesthetics and shades of portrayals of ghosts as supernatural and metaphysical realities in two Nollywood films Heart of a Ghost and A Ghost Story as representations of Igbo worldviews on ghosts' realities. Our aim is to present an analytical explanation of the filmic attributions in relation to historical as well as the subsisting socio-cultural worldviews of the Igbo people regarding ghosts. Therefore to extrapolate on the subsumed Igbo worldviews and philosophies about ghosts in the selected films, this study adopts theoretical purviews on magical realism and Charles Peirce's inclination on interpretive community theory as the preferred conceptual praxis. Furthermore, this study applies critical interpretive analysis as the adopted analytical approach. Thus, the relevance of these portrayals to the subsisting sociocultural worldviews about ghosts among the Igbo forms part of our thematic purview. Essentially this study sufficiently provides plausible answers to questions bothering on whether ghosts exist in the manner portrayed in the two films, as well as plausible analysis of the significations of ghosts' appearances in clothing and whether ghosts do change their clothing like humans from time to time.
\end{abstract}

Keywords: actual, archetypal, ghost, Igbo, imaginative visual aesthetics, magical realism, worldview

Great philosophers are so because of their ambition to build systems of thought answering a maximum of our deepest philosophical questions. (Vidal, 2008: 2)

\section{Introduction}

The film medium in many ways is like the literary arts in its mechanics and dynamics of entertaining, embedding, consolidating, and re-aligning of both culture-specific and universal ideas in the consumers. This is because watching film massages and agitates the imaginations, ideologies and inclinations of the consumers. Film "specifically, is a powerful medium that conveys the values and beliefs of contemporary societies" (Cloete 2017: 1). The results of these alluded efficacious attributes of films are usually witnessed in the ways and manner the consumers of films are propelled to either review or consolidate their worldviews as it concerns what the films they have seen encapsulate. According to Anita Cloete "film is regarded as art that is pervasive and powerful" and "as a cultural product and medium, film could be viewed as an important medium for meaning-making" because "cinema and film are embedded within culture and therefore a complex and interesting relationship exists between film, culture, ideology and

(C) AesthetixMS 2020. This Open Access article is published under a Creative Commons Attribution Non-Commercial 4.0 International License (http://creativecommons.org/licenses/by-nc/4.0/), which permits non-commercial re-use, distribution, and reproduction in any medium, provided the original work is properly cited. For citation use the DOI. For commercial re-use, please contact editor@rupkatha.com. 
the audience" (207: 1). Hence, it will not be out of place to suggest that the film-maker is in many ways a philosopher, an opinion moulder, a manipulator of emotions and a conjurer of ideas. Evidently, history is replete with instances in which film-makers consciously attempt to appropriate the film medium for the purpose of socio-political and/or cultural engineering or reengineering of the philosophical trajectories and perspectives of the target film consumers. Therefore, in response to the supposition that film as a medium, possesses the propensity to unleash both aggressive and subtle efficacious propelling force on the viewers in varying proportions, it is plausible to suggest that such efficacy can invigorate or re-invigorate the consciousness, and re-engineer the viewers' worldviews and ideologies. Our supposition here is that consciously or unconsciously, film viewers are infused with ideas after viewing films, though at different proportions. Again, another trajectory to our supposition is that the ideas conveyed through films naturally fall under one or combination of the following classification: actual, archetypal or imaginative visual aesthetics/abstract ideas.

This study attempts an analysis of meta-portrayal of ghosts in the selected films in a bid to ascertain whether the portrayals are describable as actual, archetypal or imaginative visual aesthetics/abstract representation in relation to Igbo $^{\mathrm{i}}$ worldviews on ghost appearance in clothing. What this indicates is that this study seeks to appreciate which belief system dynamics and meta-philosophy of the Igbo people, can be said to have influenced the choice of portrayals of ghosts in specific clothing in Heart of a Ghost and A Ghost Story. Thus, this study examines the degree of fidelity in representation of Igbo worldviews, philosophies and ideologies in Heart of a Ghost and $A$ Ghost Story as mystical realities. Furthermore, this study examines the possible attribution of the ghosts' appearance in specific clothing as creative aesthetics which strictly represent very little about the supposed interpretive community.

\section{Shades of Contextualisation on Key Concepts: Literature Review}

Our immediate point of departure is to clearly grasp the implicit meanings of two key concepts namely 'worldview' and 'magical realism', which are central to this paper's analytical deductions and interpretive expedition. According to David K. Naugle in his book on history of the concept 'worldview', there is evident diversity of disciplinary inclinations and approaches to the definitions of the term worldview. Based on our perusal of relevant scholarly contributions, it is clear that the academic applications of the term worldview has a long history and its applications in various academic disciplines such as religion/theology as espoused by Ezeanya (1969), EvansPritchard (1976), and van der Kooij et al (2013); on sociology/anthropology by Geertz (1973); DeWitt, (2010), Abi-Hashem \& Driscoll (2013) and Aniago et al (2016); on philosophy, politics/foreign relations and literary studies by Olthuis (1989), Oser \& Reich (1990), McKenzie (1991), Beck et al (1994) and Rousseau \& Billingham (2018), in many ways present varying degrees of differing disciplinary definitions, elaborations and emphasis. Thus we see the complexity of the mechanics of worldview and its differing definitions in the contributions made by scholars such as Kluckhohn \& Strodtbeck (1961), Hiebert (2008) in anthropology; Solomon, et al (1991), Emmons (1999), Koltko-Rivera (2004), in psychology; Ibrahim, et al (2001), Danesh \& Clarke-Habibi (2007) in Counselling; and Kuhn (1969), and Wallace (1996) in Philosophy of Science.

Expounding on the above alluded reality, David Rousseau and Julie Billingham note that "the term worldview is used differently in different disciplines" because in each discipline, scholars attempt "to emphasize a particularly relevant aspect, so that, for example, in management science, 'worldview' is typically taken to be about an individual or group's value system, while in theology, 'worldview' is often taken to be an individual's view about the existence and nature of God" (2018: 3). Furthering Rousseau and Billingham note that "worldviews are 
richer constructs" than an individual scholarly application because worldview evolves at differing proportion, and the variables that propel it are consistently re-aggregating at phenomenal complexity (2018: 3). In line with Naugle's observation, this evident diversity of definitions revolves around scholarly contextualization and conceptualization of different people's mindset, inclinations, perspectives and convictions about human realities. Rhetorically, Naugle through his question, "what could be more important or influential than the way an individual, a family, a community, a nation, or an entire culture conceptualizes reality" (2002:345), places emphasis on the centrality and importance of studies and attempts at understanding the ramifications of worldview.

In their attempt at defining worldview, Rousseau and Billingham explain that a worldview is "the overall perspective from which one sees and interprets the world in all its diversity and complexity" and that "it functions as a 'map of reality' that people use to order their lives" (2018: 3). Rousseau and Billingham's observation reflects the views of Aniago et al (2016) and Hiebert (2008), Danesh \& Clarke-Habibi (2007), Sire (2004), Naugle (2002), and Wallace (1996) on the subject. Again, from the analysis of these scholarly contributions, we observe that worldview can be categorized as either personal or collective. According to James Olthuis worldview is a vision of life which represents "a framework or set of fundamental beliefs through which we view the world, our calling and future in it" (1989: 29). Elucidating further, Olthuis explains that "this vision is a channel for the ultimate belief which gives direction and meaning to life", therefore "it is the integrative and interpretative framework by which order and disorder are judged, the standard by which reality is managed and pursued" (1989: 29). Illuminating on what an individual/personal worldview represents, Fritz K. Oser and Helmut Reich define personal worldview as "a person's mental representation of the universe (e.g. its origin, evolution, the laws governing it, its destiny), of the Ultimate Being's interactions with the universe, as well as of the position and role of human beings in the universe" (1990: 97). What the contribution of Oser and Reich indicates is that an individual normally holds personalized perspective(s) about things and realities in life beyond his or her community's shared perspectives because each person's conscious inclinations are mostly propelled by personal encounters, experiences and convictions. Similarly, Leon M. McKenzie defines individual or personal worldview as "an interpretive understanding a person reaches after reflecting on his or her experience of the world" (1991: 7). What this indicates is that an individual may have firm and abiding belief inclination about ghost realities because of personal encounters and experiences. Equally Rousseau and Billingham observe that "personal worldviews evolve as people try to integrate their knowledge, experience, and intuitions into a coherent framework, which they can use to make sense of their lives and make decisions about how to live and what to do" (2018: 3). The above line of view is variously espoused by James (1928), Emmons (1999), and Hiebert (2008) who in many ways are in accord with Rousseau and Billingham (2018).

Looking at worldview as a collective or shared reality, Clément Vidal notes that the idea of interpreting or "speaking about the worldview of a society may also seem rather far-fetched, if we do not use the metaphor of the society as an organism" therefore "those two extreme examples have however the benefit to show us the limits of the worldview concept" (2007: 7). What this perspective indicates is that worldview on ghost may be referred to as collective because of the shared communal myths, legends, and folklores that form part of the cultural knowledge of a given people. Furthering, Vidal notes that the interpretive examination of the 'worldview of a society' indicates that, "even if a worldview is ultimately carried by an individual, we should also not forget to analyse higher levels of systems or organizations with the relevant analysis at that level" (2007: 7). 
To re-emphasize on the importance of understanding worldview and how it interlinks with human conducts, projections and choice of actions, Naugle rhetorically asks: "when it comes to the deepest questions about human life and existence, does anything surpass the final implications of the answers supplied by one's essential Weltanschauung (worldview)?" (2002: 345). Therefore, it is plausible to say that the contexts of Igbo people's worldviews on ghosts as supernatural realities, when analyzed interpretively embody numerous trajectories. Thus, this study does not claim to encompass all definitions of all manifestations of socio-cultural worldviews on ghost realities but it intends to provide dependable academic discussion on examples of Igbo worldviews on ghost reality in relation to the selected films.

In his contribution on people's take on supernatural manifestations such as ghosts' appearances, Andrew Horn observes that "the forces which govern man's world are beyond his control" and these forces are "sometimes palpable - rain, earthquake, animals, diseases - and sometimes impalpable - fate, luck and the apparent breakdown and discontinuities of causality" (2014: 225). The above view is in many ways in accord with Igbo worldview on supernatural reality as demonstrated in the works of Achebe (1980), Metu (1981), Achebe (1986), Ekwunife (1990) and Nwoye (2011). To Alexander Animalu, Igbo worldview reflects an abiding acknowledgement of the influence and efficacy of the supernatural as an unavoidable force in the life of a community, thus, the Igbo reverence for "the heavens above, the earth below it and the underworld beneath the earth" (1990: 10). According to Chinwe Nwoye "the understanding among the Igbo is that spiritual beings and cosmic forces are highly intermingled" hence "the activities of spiritual beings and forces often directly impinge on the affairs of humans in the human world" (2011: 307). Thus, it is these trajectories of the interpretations of Igbo worldviews Andrew Horn notes are in many ways part of the explanation of why "to most men, both why and how these things happen are impenetrable mysteries and their world may seem a mincing anarchy" (2014: 225). Illuminating further, Horn observes that "man as a material being in a material world, fears what he perceives as immaterial, for it cannot be contained or dominated" hence "his defensive impulse is to concretise, to make the invisible visible, the infinite finite, and the superhuman human" (2014: 225). We can deduce that Horn alludes to the natural impulse in humans, which propel them to continually strive to understand more about the ethereal and numinous essence of life and the abiding acceptance by humanity that there are certain manifestations, occurrences and phenomenon that no doubt, unambiguously defy subsisting empirical deductions. It is these realities within this category, the Igbo acknowledges and classifies as supernatural realities, such as ghost phenomenon which is widely theorized as magical realism. ${ }^{\text {ii }}$

Based on our review, the application of magical realism has permeated several academic disciplines; however, there exists clear evidence of varying trajectories and perspectives to its articulation. In line with several scholarly contributions, we can say that the varying trajectories and perspectives on magical realism are propelled by existence of diverse nuances of worldviews on these manifestations, occurrences and phenomena that are describable as paranormal, supernatural, mystical or numinous. Illuminating further on the plausible reasons behind divergent perspectives, we can say that this variance exist because scholars in their interpretations draw attention to the interpretive community in relation to the significance of the geographical and culture specific contexts of magical realism. According to Isabel Allende magical realism represents "a way of seeing in which there is space for the invisible forces that move the world" such as "dreams, legends, myths, emotion, passion, and history" (1991: 54). According to Emeka Aniago et al "the convergence of opinions is that people appreciate that some realities" such as ghosts "may not yield to empirical and common sense approach to their understanding and these 
5 Metaphors of Igbo Worldviews on Ghosts as Mystical Realities: Interpretations of Filmic Portrayals as

Archetypal and Imaginative Visual Aesthetics in Two Nollywood Films

perspectives are in concordance with African worldview on mystical realism and mystical experience" (2016:15).

The idea here is that mystical reality is a universal common because reports and documentations of witnesses of examples of manifestations and phenomena describable as mystical reality are universal common, though with varied interpretive community interpretations to locale specific realities. As Maggie Ann Bowers points out, "the key to understanding how magical realism works is to understand the way in which the narrative is constructed in order to provide a realistic context" (1996: 21). Similarly, Brenda Cooper observes that "local context is of central importance in magical realist writing" and critical reading (1998: 37). These scholarly contributions indicate that magical realism provides a theoretical understanding through which scholarly attempts at interpretive appreciation and classification of diverse human experiences, perceptions, belief systems and realities such as ghost appearances can be articulated. The magical realism include what Peter Eastwell refers to as the invisible force' which are usually classified within realities and phenomena describable as those "outside the observable universe, violating natural laws, and pertaining to god or a deity and is commonly associated with things like spirituality, occultism, spirits, the divine, the miraculous, fairies, vampires, ghosts, goblins, and other unearthly beings, including angels" (2011: 18). Thus these insights will serve as foreground in our bid to discuss analytically the social perception of ghosts as mystical realities and this social perception as a product of worldview as articulated in Heart of a Ghost, and A Ghost Story within the purview of the interpretive community's worldview.

\section{Synopsis of Heart of a Ghost and A Ghost Story}

The film A Ghost Story revolves around the ghost of a murdered village girl named Kasimma who was an only child to a poor widow Chinyere who resides in an Igbo village. Chinyere vehemently refuses to accede to Ojemba's demand to be his concubine regardless of his threats. Hence enraged Ojemba (Kasimma's uncle) hires assassins who drown Kasimma in the village stream on a lonely afternoon as she fetches water because she opposes his quest. In her agony, Chinyere persistently weeps and laments to the gods regarding the loss of her only child. At some point, Kasimma's ghost begins to appear, severally tormenting all the murderers and helping individuals such as Chinyere and Ogugua.

In Heart of a Ghost, its story which happens in an Igbo village, presents how a randy bachelor Ejike whose double romantic affairs with a widow Ojiugo and her only daughter Nwando results in tragedy. Ojiugo who still loves Ejike, begs Nwando to find another man, and leave Ejike to her, but adamant Nwando vows to remain with Ejike regardless of her family's disapproval. However, when Ejike's attempt to formalize things by asking for Nwando's hand in marriage was sternly rejected by Nwando's family and kinsmen, unilaterally, Nwando moved in with Ejike and thereafter gets pregnant. One night, Ejike dreamt of Nwando's death as a result of her pregnancy complications. In the dream, Nwando's kinsmen maintained that Ejike must complete stipulated marriage rites before he could be allowed to bury Nwando's corpse. Stubbornly, Ejike refuses to promptly comply hence a stalemate, which lingered and supposedly instigated the appearances of the ghost of Nwando. Lastly, during the appearances, the ghost of Nwando sternly demands for immediate burial of her corpse repeatedly, which placed Ejike in perpetual fear. 


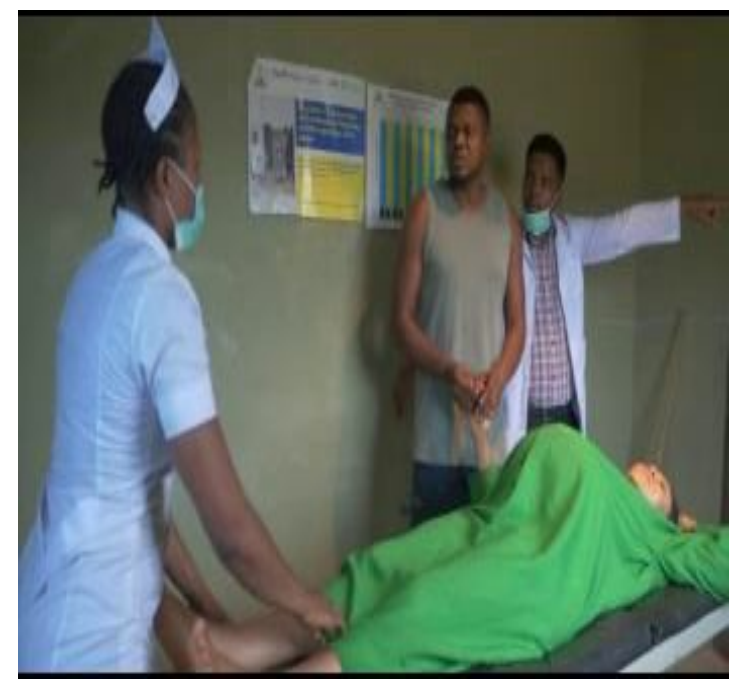

Figure 1: Nwando's corpse in green hospital the gown in Heart of a Ghost

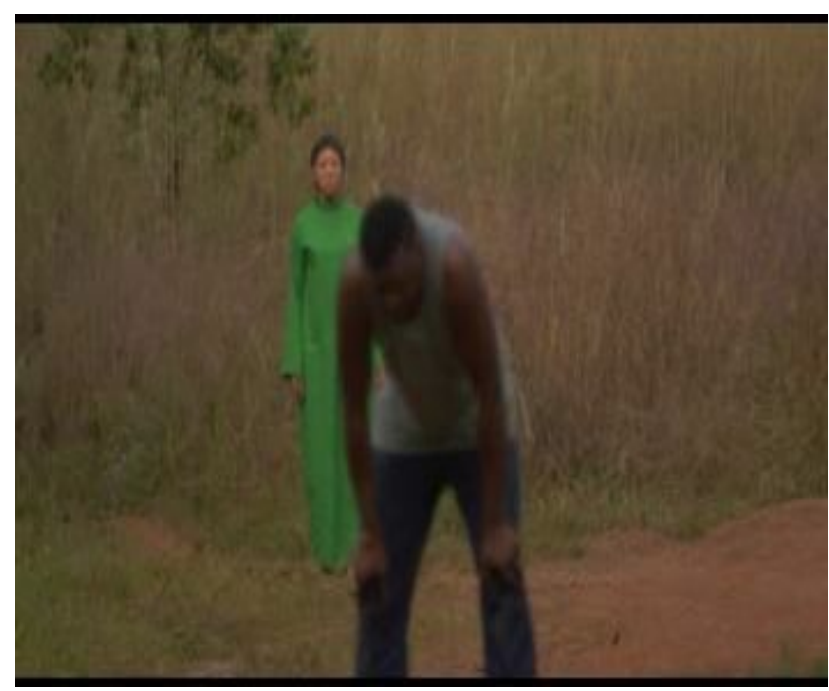

Figure 3: Nwando's ghost talking to Ejike wearing hospital gown in Heart of a Ghost
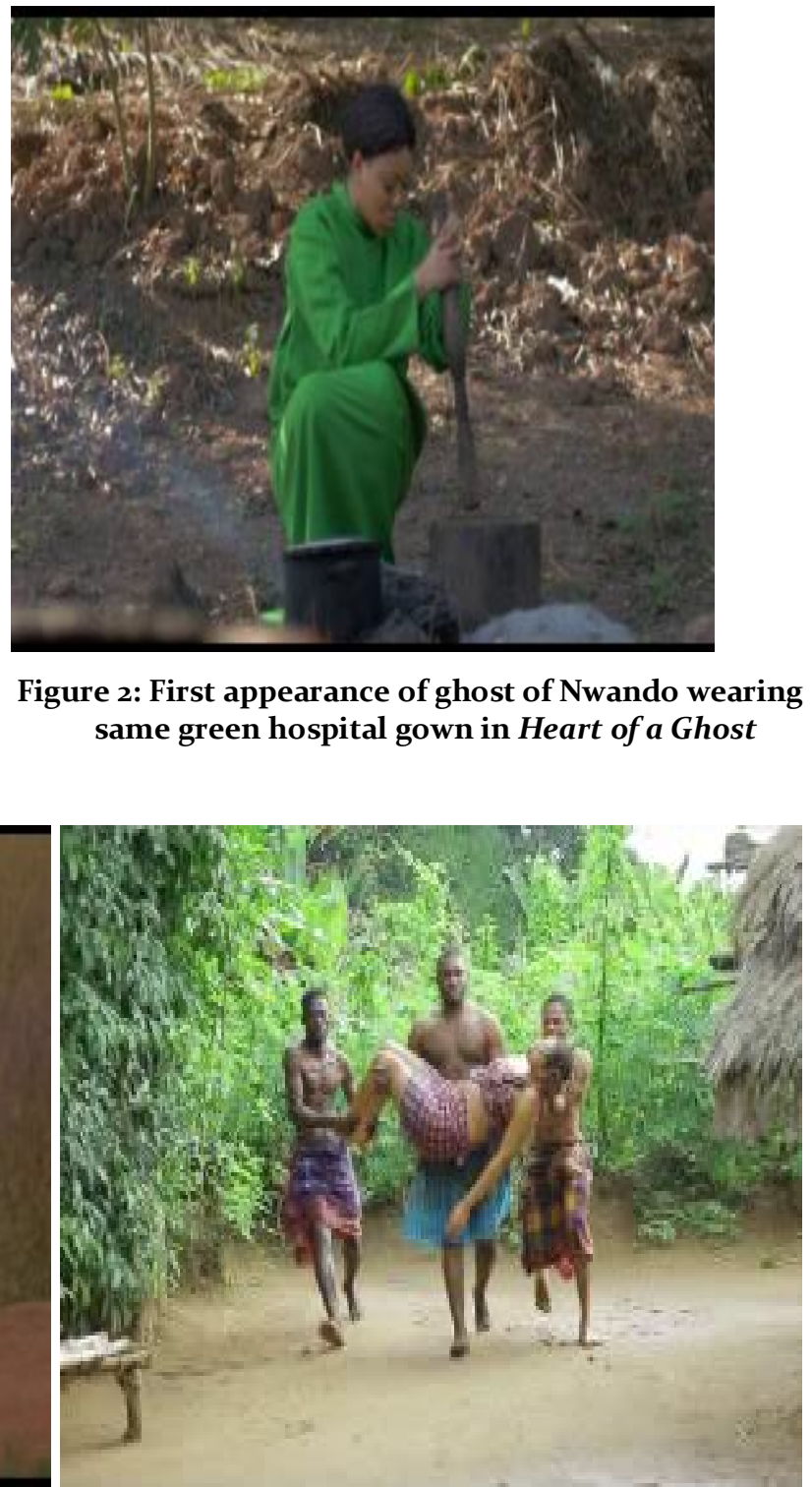

Figure 2: First appearance of ghost of Nwando wearing same green hospital gown in Heart of a Ghost

Figure 4: Men carrying corpse of drowned the same green Kasimma in A Ghost Story 


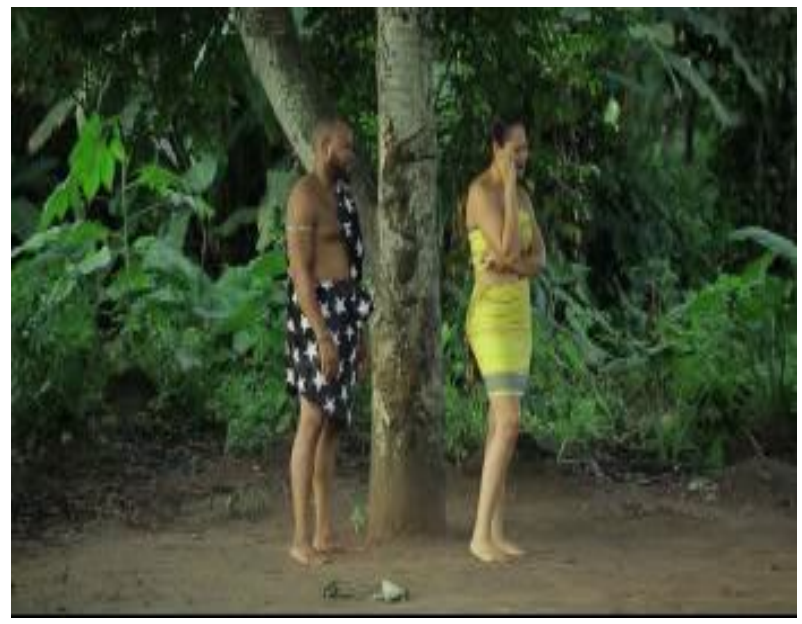

Figure 5: Ghosts of Obiajulu and Kasimma wearing black and white and yellow coloured respectively in $A$ Ghost Story

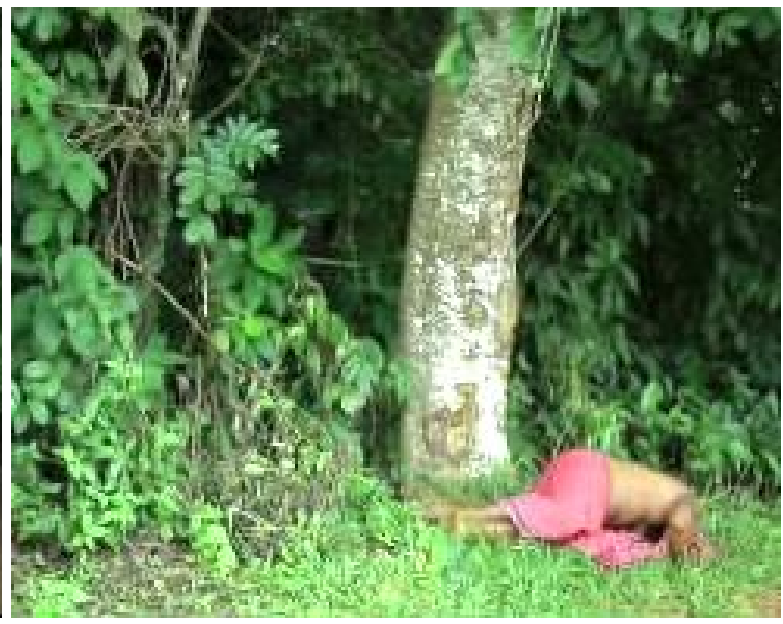

Figure 6: Obiajulu's corpse in pink wrapper in A Ghost Story colour wrappers

\section{Ghosts' Portrayals in Heart of a Ghost and A Ghost Story: Extent of Igbo Worldview Representation}

According to Murray Leeder "the cinema is full of ghosts" and the filmic representations of ghosts are "powerful, versatile metaphor" which in many ways "can signify the ways in which memory and history, whether traumatic, nostalgic, or both, linger on" within the living (2015: 1). The filmic representations of ghosts fascinates many because very many people have never seen or encountered a ghost all their lives, hence as part of the thrills, confusion, and illusion, people discuss as well as question the validity of such filmic representations as replication of the actual, archetypal or artistic creativity and imagination. However, Leeder notes that "ghosts are more than just a metaphor" (2015: 2). This is because according to Arthur Redding there is an overwhelming acknowledgement that ghosts "exit in their own right" (2011: 6). Illuminating further, Redding notes that "ghosts have legitimate power, articulate real pains and desires, and refuse fully to be explained away as figments of diseased or troubled imaginations" (2011: 6). On the widespread and abiding acceptance of ghost existence, Leeder observes that ghosts are "part of the worldview of billions, and that modernity has brought with it the hopes that we might document ghosts, objectively and scientifically, using modern media" (2015: 2). Thus Leeder observes that the "Cinema's capacity for substitutions, transpositions, and other tricks, enabled and motivated the production of ghost and poltergeist scenes" (2015: 4). In reference to the capacity of the Cinema to represent ghosts differently, Ricciotto Canudo observes that cinema permits the extraordinary and striking faculty of representing immateriality (1988).

In relation to classification ghosts' representations in films, our inclination is to go with archetypal reality because according to Crispinous Iteyo "beliefs are key components of culture, largely influencing human behaviour" and they are handed over from one generation to the other, sometimes with modifications" (2009: 152). The belief people hold about ghosts are archetypal to their cultural realities, subsumed in their myths, legends and folklores. The abiding belief that ghost existence is a universal common and that dead people may manifest as ghosts as portrayed in Heart of a Ghost and A Ghost Story are documented by several scholars such as Francis (1971), Ahern (1973), Wolf $\left(1974^{a}\right)$, Wolf $\left(1974^{b}\right)$, Metuh (1981), Ogbalu (1981), Craig (1998), Anizoba (2002), Jolly (2006), Anedo (2007), DelViillano (2007), Anedo (2008), Anthony (2009), Khair 
(2009), and Peeren (2014) in their works. The central idea here is that the acceptance of the existence of ghosts is worldview propelled and its filmic representation is to a large extent a combination of creativity and culture specific worldview attributions.

In the two films selected for this study, there are projections of some abiding Igbo worldviews on ghost manifestations and phenomena which are in tandem with the findings of Alexander Anedo and Edith Anedo, who in their study titled 'Ghosts in Chinese and Igbo Religions' observe that "both cultures recognize the presence of ghosts" (2017: 1). In both films, there are portrayals of malevolent and transmogrification propensity of ghosts in accord with Igbo worldview which Anedo \& Anedo validates, stating that "ghosts takes many forms depending on the way in which the person died" and that ghosts "are often harmful" (2017:3). In accord with the above perspective, Chinwe Nwoye observes that among the Igbo, it is believed that where designated burial "ceremony is omitted the dead man or woman goes half-way and would have to come back in visions as ghosts to disturb the living until such a time as they complete the sendoff ceremony, namely, burial rites" (2011: 310). Similarly, Henry Odera Oruka notes that Kenyans believe that spirits of the dead can be malevolent, hence they are to be feared, and depending on the circumstance, ghosts can haunt people (1991). The portrayals in Heart of a Ghost when the ghost of Kasimma began to afflict and kill the assassins and in A Ghost Story when the ghost of Nwando began to haunt Ejike demanding for the burial of Nwando's corpse, are in line with Nwoye (2011) and Oruka (1991) findings. Oruka as well as Nwoye note that when the dead are not accorded the required burial rites, there is an abiding belief in many African cultures such as the Igbo that "the spirits of the dead would haunt the people, claiming they were ignored" (Oruka, 1991: 71). Thus, in line with these positions, the portrayals of ghost of Nwando making demands for proper burial of her corpse are representations describable as archetypal Igbo worldview on ghost phenomena.

Also the projection in A Ghost Story on the capability of ghost to afflict humans in several ways such as when Ojemba was hit by a pebble thrown at him by the ghost of Obiajulu is in accord with the findings of Nwoye (2011) and Oruka (1991) as well as the submissions of two respondents Dominic Okonkwo Okoro and Donatus Anene Eze (personal Communication, Obukpa-Nsukka, March 2020). The decision of Ojemba to abort his mission and head back to his house because he is hit by a pebble from an invisible source accords with a widely acknowledged worldview inclination among Igbo people. This occurrence which is usually defined as a bad omen is mostly attributable to the machinations of angry ghosts according to Donatus Anene Eze (personal communication, Obukpa-Nsukka, March 2020). Another instance, describable as bad omen attributable to machinations of angry ghost occurred when Ojemba receives slaps from the ghost of Kasimma, the time he as visited Chinyere with the intention of sleeping her regardless of her decision. Furthermore, Ojemba was afflicted by the ghost of Kasimma who made his manhood to remain erect perpetually and this kind of affliction is viewed by the Igbo people as ominous. This worldview is corroborated by Dominic Okonkwo Okoro (personal communication, Obukpa-Nsukka, March 2020). These instances are in accord with findings of Nwoye (2011); Oruka (1991); and Anizoba (2002) who variously note that the Igbo and other Africans believe that ghosts have the capacity to hurt humans. In accord with the findings of Nwoye (2011); Oruka (1991); and Anizoba (2002), both films project Igbo people's worldview on possibility of spontaneous appearance and disappearance by ghosts. An example is when Chinyere was weeping beside Kasimma's grave in A Ghost Story; the ghost of Kasimma appeared instantaneously and stood beside Chinyere. Similarly, in Heart of a Ghost the ghost of Obiagulu appeared instantaneously and stood beside the ghost of Kasimma before both ghosts disappeared and re-appeared beside Kasimma's grave. 
Other relevant suggestions appreciable from the portrayals of Nwando's ghost in Heart of a Ghost are that ghosts can move through walls, as well as appear and disappear at will. Also the portrayals in the two films indicate that ghosts posses the ability to regulate who could hear their voice when they speak as captured in figure 2, which is in accord with the findings of Anizoba (2002) and Nwoye (2011), as well as three respondents Mathias Ojobo Okoro, Stephen Uchechukwu Asadu and Fidelia Nkechinyere Alumona (personal communication, ObukpaNsukka, March 2020). Similarly, this reality is also projected in Ghost Story as the ghost of Kasimma was able to see and hear Chinyere very well but Chinyere was not able to do same. In another instance, as the ghost of Kasimma appeared to Ojemba, while he was walking along the path-way with his family, he was the only one who could see it, his wife and son could not. The projected notion is that the ghost intends only Ojemba to see it and this portrayal is in accord with findings of Nwoye (2011); Oruka (1991); and Anizoba (2002) that ghosts can decide to make self visible and invisible at will.

Another supposition in the portrayals of ghosts in A Ghost Story is that there are some categories of humans who are endowed with supernatural powers and abilities to see, speak, and commune with ghosts, hence they see and hear ghosts whenever ghosts are around. In $A$ Ghost Story Ogugua the second daughter of Chinyere and the village priest both have ability to see, hear or perceive the presence of ghosts, whenever they are around. There is also an abiding belief that supplications with the precise rites and atmosphere can result in emergence of ghosts, thus the ghost of Kasimma is portrayed in A Ghost Story to have returned because of Chinyere's ceaseless supplications. Another trajectory to Igbo worldview on ghost realities is that ghost can assist the living in one way or the other, and this is projected in A Ghost Story when the ghosts of Kasimma and Obiajulu fetched water from the stream to fill Chinyere's water pots, swept her compound, and fetched two bundles of fire wood for her. The notion here is that the above portrayals of ghost interactions with humans are in accord with Igbo worldviews on miraculous providence and supernatural manifestations; however the portrayal of ghosts in specific clothing is an area which Igbo worldview on ghosts' realities provides little or no specification, hence such portrayals in the films Heart of a Ghost and A Ghost Story can hardly be referred to as archetypal or actual representations of Igbo worldview. However such representations may be described as artistic creativity and imaginations, hence, the need to espouse on this in the following section.

\section{Ghosts Appearances in Clothing in Heart of a Ghost and A Ghost Story as Artistic Creativity}

The signification of ghosts' appearance in a particular kind of clothing and the question of whether ghosts do change their cloths like humans from time to time in Nollywood filmic representations are areas of academic investigation that has received very little scholarly contributions. In the portrayals in the films Heart of a Ghost and A Ghost Story there are clear areas of concordance and divergence in the approaches adopted by the directors in their portrayals of ghosts in clothing. In Heart of a Ghost, the ghost of Nwando made appearances in the green hospital gown which Nwando was wearing at the time she died. Hence, the projection in this film is that ghost of a dead person should usually appear in the cloth they were wearing when they died. However, in A Ghost Story Kasimma died in purple clothing and Obiajulu died in pink clothing, but when their ghosts made all their appearances they were wearing totally different coloured clothing. The ghost of Kasimma made appearances in yellow colour clothing, whereas the ghost of Obiajulu made appearances in black and white colour clothing. This evident lack of concordance as regards to what decides or determines what kind and colour of clothing ghosts in Heart of a Ghost and A Ghost Story should appear in, indicates that more questions 
needed to be asked. In many ways, the indication here is that the two films Heart of a Ghost and $A$ Ghost Story portrayed the ghosts in clothing within divergent perspectives which we suggest emanates from speculative thinking yielded through artistic creativity and imaginations.

To learn more from the interpretive community, we developed and distributed five hundred questionnaires inquiring if the respondents have ever seen a ghost, if they have seen a ghost what is the description of the clothing they appeared in. The study target is Nsukka which is within southeast Nigeria and the interpretive community projected in the films Heart of a Ghost and $A$ Ghost Story. The respondents variously indicate through their responses that they have never seen or encountered a ghost, that their suppositions are based on stories from other people and that they cannot validate the veracity. The responses from the respondents indicate that in the 457 returned questionnaires none have ever seen a ghost and that they only got information from folktales, relatives, friends and films. However, 11 returned questionnaires claimed that their parents have told them of people who have seen ghosts, whereas 32 returned questionnaires claimed that they have had dreams were they witnessed the ghost of a known relative.

Our supposition from the interpretation of the responses from the respondents is that the filmic representations of ghosts in clothing as enacted in Heart of a Ghost and A Ghost Story are not informed by any consensus Igbo worldview rather; they are products of artistic creativity and imaginations.

Lastly, we put across the following questions as a way of indicating the praxis of difficulty the filmic representations of ghosts are confronted with. How would the ghost of a person who died in a fire incident in which he or she was completely roasted, appear in a filmic representation - clothed or nude with charred body? How would the ghost of a person who died while swimming completely naked, appear in a filmic representation - clothed or completely nude? Finally, how would the ghost of a person who slipped, hit his/her head on hard floor and died instantly appear in a filmic representation?

In response to these questions, the two concepts adopted in Heart of a Ghost and A Ghost Story in representing a ghost either in the clothing the dead died in or just in any other clothing can be of help because in all three instances provided above the individuals all died wearing no clothing. So the film-makers will be in dilemma and there are no know Igbo worldview on how a person how died naked should appear as a ghost.

\section{Conclusion}

Our position in this paper is that the acknowledgement of ghosts' realities is a universal common and it is hard to find any African ethnic group were the people strongly suggest that ghosts do not exit. Thus stories of individual experiences of witnessing ghost appearances abound globally. This goes a long way to lay credence to scholarly suppositions on preponderance of African belief in the existence and appearance of spirits and ghosts of dead people. However the information individuals' claim and present about their ghost citing experiences are not usually verifiable. Therefore, the claims about ghosts' appearances and activities can hardly be subjected to empirical verifications. Essentially, this study's assessment of the approaches to the portrayals of ghosts in Heart of a Ghost and A Ghost Story indicates that filmic representations of ghosts in the above mentioned Nollywood films are in some cases describable as products of artistic creativity and imaginations and in other cases an adherence to Igbo worldviews. Hence, this study affirms that filmic representations of ghosts in Nollywood films such as Heart of a Ghost and A Ghost Story usually rely significantly on artistic creativity and imaginations to present ghosts manifestations because they are part of mystical realities which do not have empirical 
explanations. This affirms that the categories of portrayals in Heart of a Ghost and A Ghost Story are those that depict common place mythical worldviews, overt fantasy, and typical examples of claimed true-life experiences as well as typical examples of widely documented manifestations in several climes, though without empirical validations. Hence, the presentations of ghosts in films are mostly empirically non-verifiable artistic creativity and imaginations.

In this study, we explained that worldview is a trajectory of social construction of reality, and that what people profess, suggest, believe, and think they know about ghost realities are majorly phenomena of social construction of worldview. We also alluded that both individual and communal perceptions on ghosts are not permanent but fluid because the variables that alter social perceptions - the way people see and take things - (worldview) is continually in consistent aggregation at varying pace to individuals and communities.

\section{Notes}

${ }^{\mathrm{i}}$ Igbo is a language spoken by Igbo people of the Igbo ethnic group, one of the three major ethnic groups in Nigeria. The group is indigenous to the Southeastern part of the country, mostly on the eastern side of the Niger River, a region considered to be one of the most densely populated regions in the whole of Africa.

ii The term magical realism at its introduction in the 1920s, applied to a school of surrealistic German painters, however, later in the 1940s and 1950s, it made its way into literary analysis. Thus literary critics and theorists began to apply the concept of magical realism in classifying and explaining nuances of the mystical in various literary genres. Some prominent literati whose works were viewed within the premise of magical realism include Jorge Luis Borges in Argentine, Isabel Allende in Chile, Gabriel Garcia Mărquez in Colombia, Günter Grass in German, Italian Italo Calvino, Salman Rushdie and John Fowles in England, and the Nigerian duo of Amos Tutuola in The Palm-Wine Drinkard, and Ben Okri in The Famished Road.

\section{References}

Abi-Hashem, N., \& Driscoll, E. G. (2013). "Cultural anthropology" Encyclopaedia of Cross-cultural Psychology. K. D. Keith (Ed.), Malden: Wiley-Blackwell, pp. $292-295$

Achebe, C. C. (1986). The World of the Ogbanje. Enugu: Fourth Dimension Publishing Co. Ltd.

Achebe, C.C. (1980). "Literary Insights into the Ogbanje Phenomenon" Journal of African Studies, Vol. 7, No. 1 , pp. $31-38$.

Ahern, Emily M. (1973). The Cult of the Dead in a Chinese Village. Stanford, California: Stanford University Press.

Allende, I. (1991). "The Shaman and the Infidel" (interview) New Perspectives Quarterly, Vol. 8, No. 1, pp. 54 -58 .

Anedo A. A. O. \& Anedo, E. N. (2017). "Ghosts in Chinese and Igbo Religion" Journal of African Studies \& Development, Vol. 13, pp. $1-14$.

Anedo, A. A. O. (2008). "Neglect of Ancestors (Ndiichie): The Bane of Modern Igbo Problems." The 4th Conference \& Seminar of the Igbo Studies Association, at the University of Nigeria, Nsukka from $16^{\text {th }}-$ $20^{\text {th }}$ September

Aniago, E., Onah, J. O. \& Ogu, D. I. (2016). "Mystical Dimensions of Prayer in Ahmed Yerima's Idemili: Human Quest to Learn" Research on Humanities and Social Sciences, Vol.6, No.22, pp. 13 - 18.

Animalu, A. O. E. (1990). "Ucheakonam” Ahiajoku Lecture. Owerri: Imo State Ministry of Information, Culture, Youth \& Sports.

Anizoba, O. M. (2002). "Ancestral Presence in African Traditional Religion: The Igbo Perspective” Unizik Journal of Arts and Humanities, Vol. IV, pp 77 - 89. 
Anthony, O. (2009). Paper Offerings for the Dead. London: Warhol.

Beck, U.; Giddens, A.; \& Lash, S. (1994). Reflexive Modernization: Politics, Tradition and Aesthetics in the Modern Social Order. Stanford, CA: Stanford University Press.

Bowers, A. M. (2004). Magical Realism. London: Routledge.

Canudo, R. (1988). "Reflections on the Seventh Art," in French Film Theory and Criticism: A History/Anthology, 1907-1939, V1, ed. Richard Abel, Princeton: Princeton University Press, pp. 300-1.

Cloete, A. L. (2017). "Film as Medium for Meaning Making: A Practical Theological Reflection" HTS Teologiese Studies/Theological Studies, Vol. 73, No. 4, pp. $1-6$.

Cooper, B. (1998). Magical Realism in West African Fiction: Seeing with a Third Eye. London: Routledge.

Craig, E. (Ed.) (1998). Routledge Encyclopaedia of Philosophy, Vol. 9. London: T.J. International.

Danesh, H. B., \& Clarke-Habibi, S. (2007). "The Concept of Worldview" in Education for Peace Curriculum Manual, Vancouver: EFP-International Press, pp. 29-6o.

DelVillano, B. (2007). Ghostly Alterities: Spectrality and Contemporary Literatures in English. Stuttgart: Ibidem-Verlag.

DeWitt, R. (2010). Worldviews: An Introduction to the History and Philosophy of Science ( ${ }^{\text {nd }}$ ed). Malden: Wiley-Blackwell

Eastwell, P. (2011). "Supernatural Explanations: Science or Not” Science Education Review, Vol. 10, No. 1, pp. $17-26$.

Emmons, R. A. (1999). The Psychology of Ultimate Concerns: Motivation and Spirituality in Personality, ${ }^{\text {st }}$ ed.; Guilford Press: London, UK.

Evans-Pritchard, E. E. ([1937] 1976). Witchcraft, Oracles, and Magic among the Azande. Oxford: Clarendon.

Ezeanya, S. N. (1969). "God, Spirits, and the Spirit World" in Biblical Revelation and African Beliefs. K. A. Dickson \& P. Ellingworth (edts) Maryknoll: Orbis, pp. 30-46.

Francis, L. K. H. (1971). Under the Ancestors' Shadow: Kinship, Personality, and Social Mobility in China. California: Stanford University Press.

Geertz, C. (1973). Interpretation of cultures: Selected essays by Clifford Geertz. New York: Basic Books.

Hedlund-de Witt, A. (2912). "Exploring Worldviews and their Relationships to Sustainable Lifestyles: Towards a New Conceptual and Methodological Approach” Ecol. Econ. Vol. 84, pp. 74-83.

Hiebert, P.G. (2008). Transforming Worldviews: An Anthropological Understanding of How People Change, Grand Rapids: Baker Academic.

Horn, A. (2014). "Ritual, Drama and the Theatrical: The Case of Bori Spirit Mediumship" Drama and Theatre in Nigeria: A Critical Source Book. ( $2^{\text {nd }}$ Ed) Yemi Ogunbyi (ed). Ikeja: Tanus Books, pp. $222-249$.

Ibrahim, F. A., G. Roysircar-Sodowsky, \& H. Ohnishi. (2001). "Worldview: Recent Developments and Needed Directions" in Handbook of multicultural counselling, ed. J. G. Ponterotto, J. M. Casas, L. A. Suzuki, \& C. M. Alexander, 425-456. Thousand Oaks, CA: Sage.

Iteyo, C. (2009). "Belief in the Spirits of the Dead in Africa: A Philosophical Interpretation Thought and Practice" A Journal of the Philosophical Association of Kenya, Vol. 1, No. 1, pp. 147 - 159.

James, W. (1902). The Varieties of Religious Experience: A Study in Human Nature, being the Gifford Lectures on Natural Religion Delivered at Edinburgh in 1901-1902; [cited edition is 36th impression published in 1928]; London: Longmans Green.

Jolly, M. (2006). Faces of the Dead: The Belief in Spirit Photography. London: British Library.

Khair, T. (2009). The Gothic, Post-colonialism and Otherness: Ghosts from Elsewhere. Houndmills, Basingstoke: Palgrave Macmillan.

Kluckhohn, F. \& Strodtbeck, F. (1961). Variations in Value Orientations. Evanston, IL: Rowand Petterson.

Koltko-Rivera, M. (2004). "The Psychology of Worldviews" Review of General Psychology, Vol. 8, No. 1, pp. 3-58.

Kuhn, T (1969). The Structure of Scientific Revolutions. Chicago: University of Chicago Press.

Leeder, M. (2015). "Introduction" Cinematic Ghosts: Haunting and Spectrality from Silent Cinema to the Digital Era, Murray Leeder (Ed), New York: Bloomsbury Academic, pp. 1 - 14.

McKenzie, L. (1991). Adult Education and Worldview Construction. Malabar, FL: Krieger Publishing Company. 
Metuh, I. E. (1981). God and Man. New York: Macmillan.

Naugle, D. (2002). Worldview: The History of a Concept. Cambridge: Eerdmans Publishing.

Nwoye, C. M. A. (2011). "Igbo Cultural and Religious Worldview: An Insider's Perspective" International Journal of Sociology and Anthropology, Vol. 3, No. 9, pp. 304 - 317

Ogbalu, F. C. (1981). Igbo Culture and Institutions. Onitsha: Versity Press.

Olthuis, J. H. (1989). "On Worldviews" in Stained Glass: Worldviews and Social Science, P. A. Marshall, S, Griffioen, \& R. J. Mouw. (edts) Lanham, Md: University Press of America, pp. 26-40.

Oruka, H. O. [ed]. (1991). Sage Philosophy: Indigenous Thinkers and Modern Debate on African Philosophy. Nairobi: Acts Press.

Oser, F. \& Reich. H. (1990). "Moral Judgment, Religious Judgment, Worldview and Logical Thought: A Review of their Relationship, part one" British Journal of Religious Education, Vol. 12, No. 2, pp. 94-101.

Peeren, E. (2014). The Spectral Metaphor: Living Ghosts and the Agency of Invisibility. Houndmills, Basingstoke: Palgrave Macmillan.

Redding, A. (2011). Haints: American Ghosts, Millennial Passions, and Contemporary Gothic Fiction. Tuscaloosa: The University of Alabama Press.

Rousseau, D. \& Billingham, J. (2018). "A Systematic Framework for Exploring Worldviews \& Its Generalization as a Multi-Purpose Inquiry Framework” Systems, Vol. 6, No. 27, pp. 1- 20.

Sire, J. W. (2004). Naming the Elephant: Worldview as a Concept, Downers Grove, IL: IVP Academic.

Solomon, S., Greenberg, J. \& Pyszczynski. T. (1991). "A Terror Management Theory of Social Behaviour: The Psychological Functions of Self Esteem \& Cultural Worldviews” Advances in Experimental Social Psychology, Vol. 24, pp. 93-154.

van der Kooij, J. C., de Ruyter, D. J. \& Miedema, S. (2013). "Worldview: The Meaning of the Concept and the Impact on Religious Education" Religious Education, Vol. 108, No. 2, pp. 210-228.

Vidal, C. (2007). An Enduring Philosophical Agenda. Worldview Construction as a Philosophical Method, Submitted for publication. Available at http://cogprints.org/6048/

Vidal, C. (2008). Wat is een wereldbeeld? (What is a worldview?), in Van Belle, H. \& Van der Veken, J., Editors, Nieuwheid denken. De wetenschappen en het creatieve aspect van de werkelijkheid, in press. Acco, Leuven.

Wallace, W. A. (1996). The Modelling of Nature: Philosophy of Science and the Philosophy of Nature in Synthesis, Washington, DC: The Catholic University of America Press.

Wolf, A. P. (1974 $\left.{ }^{\mathrm{a}}\right)$. Religion and Rituals in Chinese Society. Stanford: Stanford University Press.

Wolf, A. P. (1974 ). "Gods, Ghosts and Ancestors" in Religion and Ritual in Chinese Society. Arthur P. Wolf (ed). Stanford: Stanford University Press.

\section{Films Cited}

A Ghost Story. Dir. Bobemmanuel Anosike. English. Ama-Right Movies Production Ltd, Nigeria. 2017 Heart of a Ghost. Dir. Goodnews Erico Isiaka. English. De Blessed NnaPeace Production Ltd, Nigeria. 2019 